Exp Brain Res (1985) 58: 455-472

\title{
Frontal lobe lesions in man cause difficulties in suppressing reflexive glances and in generating goal-directed saccades
}

\author{
D. Guitton, H.A. Buchtel ${ }^{1}$, and R.M. Douglas ${ }^{2}$ \\ Department of Neurology and Neurosurgery, McGill University and Montreal Neurological Institute, \\ 3801 University Street, Montréal, Québec, Canada H3A 2B4
}

Summary. The frontal eye field (FEF) and superior colliculus (SC) are thought to form two parallel systems for generating saccadic eye movements. The $\mathrm{SC}$ is thought classically to mediate reflex-like orienting movements. Thus it can be hypothesized that the FEF exerts a higher level control on a visual grasp reflex. To test this hypothesis we have studied the saccades of patients who have had discrete unilateral removals of frontal lobe tissue for the relief of intractable epilepsy. The responses of these patients were compared to those of normal subjects and patients with unilateral temporal lobe removals. Two tasks were used. In the first task the subject was instructed to look in the direction of a visual cue that appeared unexpectedly $12^{\circ}$ to the left or right of a central fixation point (FP), in order to identify a patterned target that appeared $200 \mathrm{~ms}$ or more later. In the second "anti-saccade" task the subject was required to look not at the location of the cue but in the opposite direction, an equal distance from FP where after $200 \mathrm{~ms}$ or more the patterned target appeared. Three major observations have emerged from the present study. (a) Most frontal patients, with lesions involving both the dorsolateral and mesial cortex had long term difficulties in suppressing disallowed glances to visual stimuli that suddenly appeared in peripheral vision. (b) In such patients, saccades that were eventually directed away from the cue and towards the target were nearly always triggered by the appearance of the target itself irrespective of whether or not the "anti-saccade" was preceded by a disallowed glance. Those eye movements away from the cue were only rarely generated

\footnotetext{
Present addresses: 1 Depts. of Psychiatry and Psychology, University of Michigan and Psychology Service, VA Medical Center, Ann Arbor, MI 48105, USA

2 Aviation Medical Research Unit, Department of Physiology, McGill University, Montréal, Québec, Canada

Offprint requests to: D. Guitton (address see above)
}

spontaneously across the blank screen during the cue-target time interval. (c) The latency of these visually-triggered saccades was very short (80-140 ms) compared to that of the correct saccades (170-200 ms) to the cue when the cue and target were on the same side, thereby suggesting that the structures removed in these patients normally trigger saccades after considerable computations have already been performed. The results support the view that the frontal lobes, particularly the dorsolateral region which contains the FEF and possibly the supplementary motor area contribute to the generation of complex saccadic eye-movement behaviour. More specifically, they appear to aid in suppressing unwanted reflex-like oculomotor activity and in triggering the appropriate volitional movements when the goal for the movement is known but not yet visible.

Key words: Frontal lobes - Frontal eye fields - Eyemovements - Saccades

\section{Introduction}

The frontal lobes reach their apogee of expansion in the human brain and thus are considered to be the latest of brain structures to have developed in the course of phylogeny. Concurrent with this notion is the observation that frontal lobe ontogenetic development is slow and myelination is not complete until long after birth (Conel 1939). Consequently, these cortical structures are considered to be implicated in the genesis and control of the most complex behaviours. Fuster (1981) has recently reviewed the role of prefrontal cortex in motor control. In his words "the motor acts for which the prefrontal cortex appears essential can be characterized as the 'least 
automatic'... and the most dependent on planning and deliberation". In this paper we shall consider this view as applied to the oculomotor system. Two frontal cortical areas are thought to be implicated in the control of eye movements: the frontal eye field (FEF) and the supplementary motor area (SMA) (Melamed and Larsen 1979). Compared to the FEF very little is known about the role of the SMA. The FEF has long been thought to be the cortical command center controlling voluntary (saccadic) eye movements. Indeed, unilateral FEF ablation causes an immediate, and transient neglect of objects in the contralateral visual field, deviation of the head and eyes to the side of the lesion, and an incapacity to perform voluntary saccades towards the contralateral side (Kennard and Ectors 1938; Welch and Stuteville 1958; Heilman and Valenstein 1972). Bilateral ablation has been reported to result in a fixed gaze directed straight ahead with, transiently, no eye movements (Kennard and Ectors 1938). The hypothesis that the FEF is an important cortical oculomotor area has been strengthened by noting its proximity to motor cortex, its contribution to the pyramidal tract (Bizzi 1968; Kuypers and Lawrence 1967) and the short latency and low threshold of the saccadic eye movements evoked by focal electrical stimulation (Robinson and Fuchs 1969). Recent unit recording experiments have strongly implicated the FEF in the genesis of visually guided saccadic eye movements (Wurtz and Mohler 1976; Bruce and Goldberg 1981; Goldberg and Bruce 1981; Goldberg and Bushnell 1981; Bruce and Goldberg 1985). Specifically, the experiments of Bruce and Goldberg (1985) have revealed a large number of neurons whose discharges are related to both visual stimulation and saccades but which respond only before visually triggered saccades. Their results emphasize the "motor" function of the FEF since discharges related to eye movements (movement fields: Sparks and Mays 1980) need not be caused by prior visual stimulation of the visual receptive field of the cell, it being only necessary that the visual stimulus, via previous training, indicate the appropriate amplitude and direction for the saccade.

Another structure that is essential to the programming of saccades is the superior colliculus (SC). Schiller et al. (1980) have shown that ablation of both the FEF and SC together drastically impairs the ability of monkeys to make saccades. Classically the $\mathrm{SC}$ has been considered essential to the programming of reflexive saccadic eye movements (the "visual grasp reflex", Hess et al. 1946). In terms of the development of a conceptual model of FEF function an attractive hypothesis is that the frontal lobes and the FEF in particular can exert higher level control over simple reflex-like evoked saccades. This was originally proposed by Holmes (1938) who postulated that "the frontal centres... keep under control, or inhibit, reflexes that are not appropriate to our conduct or our reactions to the world around us." Today, there is considerable evidence showing that frontal animals are hyperactive, distractable, or have more specifically, difficulty in suppressing orienting reactions to novel stimuli (Butter 1964; Hannon and Kamback 1972; Mishkin 1964; Pribram 1961; Jeannerod 1972; Zernicki 1972; see also review by Fuster 1981). Thus the FEF could be thought of as imposing some higher level control on the reflex foveating mechanism.

In the present experiments, we have tackled this hypothesis by using a task that illustrates, in the simplest possible way, voluntary control over a reflexive glance. In this "anti-saccade" task (Hallett 1978, Hallett and Adams 1980) subjects were required not to look at a flashed visual cue but rather to look away from it. The relative cognitive simplicity of the anti-saccade task plus the ease with which humans can be instructed to perform it, make this task ideal as an initial human experiment, preliminary to an eventual combined animal-neurophysiological experiment. We have therefore studied frontal and temporal patients and have compared their responses to those of normal subjects. One of the principal findings confirmed our working hypothesis and showed that frontal lobe patients had a striking impairment in their ability to suppress a disallowed reflexive glance at the stimulus. A brief description of some of these results has been published earlier (Guitton et al. 1982).

\section{Methods}

Thirty-three subjects were studied altogether. Of these, ten young adult patients ( 7 females, 3 males, hereafter called frontal patients or frontals), had discrete unilateral removal of frontal lobe tissue for the relief of intractable epilepsy, and were studied at about the second week that followed the operation. Their cortical excisions are depicted in a schematic lateral view of each brain, shown opposite the bar graph in Fig. 9. Seven other frontal patients ( 2 females, 5 males one of which, RM, had also been studied two weeks post-operatively) were studied 1-22 years post-operatively. Their lesions are shown in Fig. 13. Some tissue removals were limited to "islands" of cortex, whereas others were close to being complete unilateral frontal lobectomies (patients $\mathrm{CH}, \mathrm{BG}, \mathrm{JB}$ and MS). Six of the frontal patients (LG, YG, EK, CH, BG, MS) had probable FEF lesions (see Results). Two control groups, composed also of young adults, were studied. These consisted of 9 normal subjects ( 4 females, 5 males) and 7 patients ( 1 female, 6 males, hereafter to be called temporal patients or temporals), with lesions of similar etiology, who had undergone discrete temporal lobe removals performed two weeks earlier. The epileptogenic lesions were generally static and atrophic: of the 24 patients studied all 
Table 1. Frontal patients tested two weeks post-operatively: results of psychological examination ${ }^{\mathrm{a}}$

\begin{tabular}{|c|c|c|c|c|c|c|c|c|c|c|c|c|}
\hline \multirow[t]{2}{*}{ Test } & \multicolumn{4}{|c|}{ Lesion on left } & \multicolumn{8}{|c|}{ Lesion on right } \\
\hline & YG & RM & SK & Mean & EK & LG & SB & $\mathrm{JH}$ & $\mathrm{JR}$ & JF & $\mathrm{CH}$ & Mean \\
\hline IQ & 76 & 94 & 101 & $90.3 \pm 12.9$ & 104 & 97 & 90 & 115 & 103 & 86 & 99 & $99.1 \pm 9.6$ \\
\hline CS & 3 & 3.3 & 3.3 & $3.2 \pm 0.2$ & 6 & 6 & 6 & 6 & 6 & 6 & 6 & $6 \pm 0$ \\
\hline WF & 10 & 5 & 14 & $9.7 \pm 4.5$ & 14 & 26 & 14 & 49 & 47 & 25 & 37 & $30.3 \pm 14.4$ \\
\hline
\end{tabular}

${ }^{\text {a }}$ Scores are given for the Wechsler I.Q. test (IQ); Wisconsin card sorting test (CS) and the Thurstone word fluency test (WF). Average IQ $=90-110 . \mathrm{CS} \leq 3$ corresponds to failure on this test. WS $\leq 30$ corresponds to failure. See Milner (1975)

except 4 frontals (RM, EK JH and MS) had seizures dating from childhood. It will be noted that two patients (SK, JF), that had both frontal and temporal lobe lesions, were classified here as frontals. This is because they, unlike patients with lesions strictly restricted to a temporal lobe, showed the same deficiencies as the purely frontal patients (see Results).

Each patient was subjected, both preoperatively and 2-3 weeks postoperatively, to extensive psychological testing on a variety of tasks. Table 1 shows, for each frontal patient that was tested two-weeks postoperatively on the anti-saccade task, the scores obtained on three well established tests administered at about the same time: the Wechsler I.Q. test (IQ); the Wisconsin card sorting test (CS); and the Thurstone word fluency test (WF) (Milner 1975). The latter two tests are particularly sensitive to left frontal lesions (ibid). Table 1 shows that the IQ score was in the normal range indicating that a decrease in the general intelligence level of the frontal patients cannot account for difficulties in performing the antisaccade task. Furthermore, the left frontals, but not the right frontals, showed as expected considerably greater impairment on the CS and WF tests but the deficits observed in our task were not side dependent.

Each subject sat with his chin on a molded rest to eliminate head movements and with his eyes $80 \mathrm{~cm}$ from a large cathode ray oscilloscope screen (Hewlett Packard, Model 1310 with short persistence phosphor, type P 31). The room lights were dim but bright enough that the experimenter could take notes, and the subject viewed the screen through an opening in a cone-shaped hood designed to eliminate reflections and shadows from the screen and other distracting visual stimuli. Eye movements were measured by electrooculography (EOG). The binocular EOG potential was measured in the horizontal plane across both eyes with an electrode placed near the external canthus of each. A computer sampled the EOG signal at $250 \mathrm{~Hz}$ and stored the data along with internal information on the spatio-temporal characteristics of the cue-symbol presentation.

Visual stimuli that appeared on the screen were computergenerated. On the screen there first appeared a small cross-shaped central fixation point (FP) (Fig. 1). After a short but variable time $(0.5-3 \mathrm{~s})$ the FP was extinguished and a stimulus cue consisting of a small square, of size one degree by one degree, appeared for $100 \mathrm{~ms}$ randomly $12^{\circ}$ either to the left or right of the FP. Eye movements triggered by this cue normally had a latency greater than $150 \mathrm{~ms}$ and were therefore made with the screen blank.

Two tasks were run separately. In the classic foveation task, called here the 'pro-saccade' task (usually run first) the subject was instructed to look at the cue. In the 'anti-saccade' task, the subject was told not to look at the cue but rather to look in the opposite direction, an equal distance from the FP. At times ranging normally from about $300-600 \mathrm{~ms}$ after the onset of the cue, a patterned target hereafter to be called the symbol - a $1 / 2^{\circ}$ square with a gap on one side and surrounded by a square identical to the cue stimulus - eventually appeared for $150 \mathrm{~ms}$ either at the same location (pro-saccade task) or on opposite side (anti-saccade task) from the cue. The time interval between the onsets of the cue and symbol will be called $\Delta \mathrm{T}$. After the symbol was turned off it was replaced by a "mask" having the shape of a large asterisk. The eye movement amplitude suggested that correct identification of the gap's location required the eyes to be within about $1 / 2^{\circ}$ of the target. The response of a subject was non-verbal: the gap's location was indicated by orienting the right thumb in the proper direction, either left, right, up or down. When they were uncertain of the answer some subjects said so, others guessed. Subjects were given verbal instructions accompanied by schematics depicting the experimental conditions. The subjects knew the task type but not the side of the cue. Patients were usually only available for a maximum of about $1 \frac{1}{2} \mathrm{~h}$ and the experimental sessions were therefore limited in scope. In this time it was found that most subjects could be tested with the following sequence of runs: (1) "easy" pro-saccade; (2) "easy" anti-saccade; (3) "difficult" antisaccade; and (4) "difficult" pro-saccade. A run consisted of 80 presentations or trials. In the "casy" and "difficult" pro-saccade tasks $\Delta \mathrm{T}$ was $400 \mathrm{~ms}$ and $300 \mathrm{~ms}$ respectively. In the "easy" and "difficult" anti-saccade tasks these times were respectively $600 \mathrm{~ms}$ and $400 \mathrm{~ms}$. Ten to 15 practice presentations were allowed at the beginning of the first prosaccade and anti-saccade runs with the experimenter providing verbal feedback on whether the gap's location was correctly identified. During the actual trials no such feedback was given.

\section{Results}

\section{Pro-saccade task}

Frontal and temporal patients had absolutely no difficulty in performing the pro-saccade task. In view of the classical notion that the FEFs control voluntary eye movements, it is particularly important to note that those frontal patients whose lesions almost certainly invaded all or most of the FEF territory (e.g. patients $Y G, E K$ and $L G$ ) and who had important deficits on the anti-saccade task, could not be distinguished from the other frontal or temporal patients in the pro-saccade task. Figure 2 compares pro-saccades made by frontal patient LG with those made by temporal patient $\mathrm{FW}$ to a target presented on the side contralateral to the lesion. The bottom trace indicates the timing of the sequential phases of the pro-saccade task. For the cases illustrated there was a period of $300 \mathrm{~ms}$ between the onset of the cue and the onset of the symbol. The vertical dashed line, 


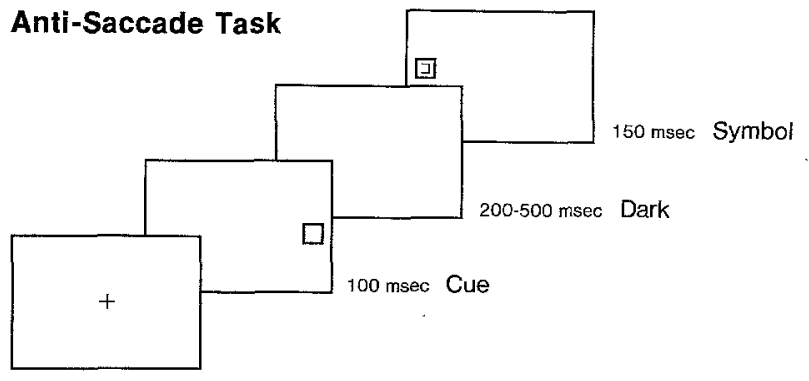

Fig. 1. Diagrammatic representation of the anti-saccade task. The subject faces a large screen cathode-ray oscilloscope on which there is a central fixation point (FP small cross in the rectangle in the bottom left). After a short random time the FP is extinguished and a stimulus cue appears for $100 \mathrm{~ms}$ randomly either $12^{\circ}$ to the left or $12^{\circ}$ to the right. The subject must not look in the direction of the cue but in the opposite direction, an equal distance from the FP, where a symbol (a square with a gap in it) will shortly appear. The task is to indicate with the thumb whether the gap is left, right, up or down. Task difficulty can be increased by decreasing the interval between cue and symbol

that joins the upper and lower timing traces, indicates the onset of the cue. In this figure as well as in Figs. 5- 8 the trials have been ranked by the computer in order of increasing latency and the "check". mark on the left of each trace indicates that the subject correctly identified the location of the gap in that trial. (Note that this ranking of trials does not hide early practice effects since a subject's performance stabilized at the end of each practice session that preceded a run.) The irregularities that appear towards the end of most of FW's eye movement traces are movement artefacts linked to this subject's vigorous responses when indicating the location of the gap. Fewer traces are shown for LG because 9 were rejected due to inaccurate fixation of FP at the start of a trial. (Inaccurate fixation of FP was unusual in both frontal and temporal patients.) Both the latency of the pro-saccades and the accuracy with which the symbol was identified were similar in these two patients when the goal was either contralateral to the lesion (Fig. 2) and therefore the saccade was being driven by the damaged hemisphere, or ipsilateral to the lesion (not shown). Figure 3A shows the mean latencies of pro-saccades made by the subjects tested. Table 2 shows individual values.

In our normals ( 8 of the 9 subjects being righthanded) there was a nonsignificant $7 \mathrm{~ms}$ difference between the latencies of left-going $(159 \mathrm{~ms})$ and right-going (166 ms) pro-saccades $(\mathrm{t}(16)=0.58$, $p>0.20$ ). This lack of laterality is in agreement with Hallett and Adams (1980). The mean latencies for the temporal group were $184 \mathrm{~ms}$ and 196 for pro-saccades directed towards the ipsilateral and contralateral sides respectively. For the frontals the means were

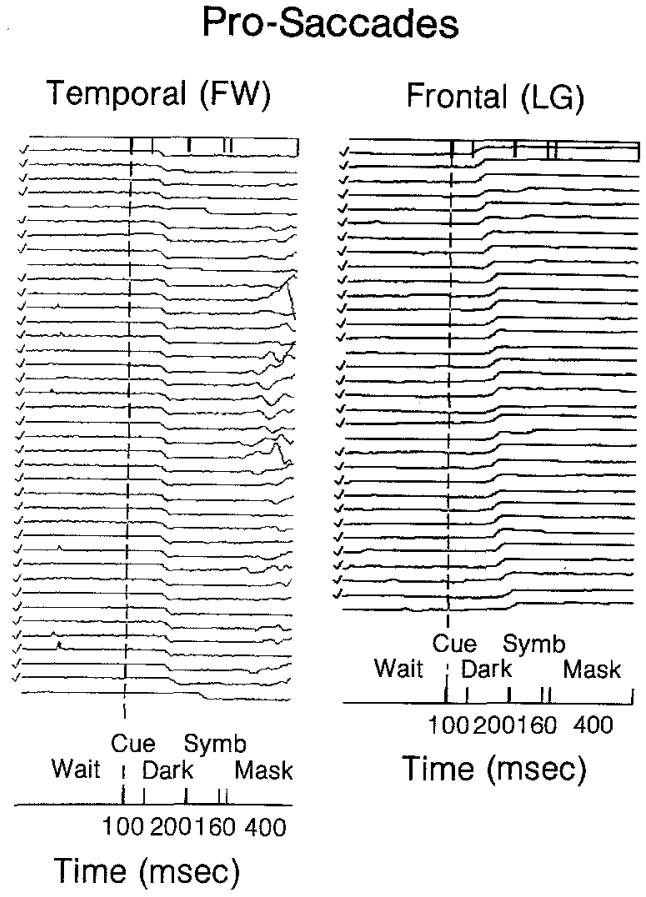

Fig. 2. Pro-saccade task. Examples of the normal saccadic eye movement responses generated by a damaged hemisphere. The group of traces on the left show leftward directed saccades made by a patient (FW) who had a right temporal lobe excision. The traces on the right show leftward directed saccades, generated by a right frontal lobe patient (LG). Note that for FW a left saccade is represented by a downward deflection whereas for $\mathrm{Lg}$ it is an upward deflection. In each example the topmost and bottommost traces are the time scales which indicate for example that the cuesymbol time interval $(\Delta \mathrm{T})$ was $300 \mathrm{~ms}$. Between these time markers are the saccadic eye movement responses which have been ranked by the computer in order of increasing latency. A check-mark on the left of an eye movement trace indicates that the subject correctly identified the gap location in that trial. The vertical dotted line indicates the onset time of the cue. The saccade traces for patient FW terminate noisily due to a movement artefact generated by this subject's vigourous arm response when signalling the gap's location

$165 \mathrm{~ms}$ and $171 \mathrm{~ms}$ respectively. The latencies of prosaccades made by the frontal and temporal patients were compared using an analysis of variance for twofactor experiments with repeated measurements on one factor (Ferguson 1981). The factors were: group (temporal or frontal), and direction of saccade relative to the damaged side (ipsilateral or contralateral). The mean latencies of each of the temporal and frontal groups did not differ significantly $(\mathrm{F}(1,15)=$ 2.83, $p>0.05)$. There was also no significant difference between the population means for prosaccades directed ipsilaterally and contralaterally $(\mathrm{F}(1,15)=2.40, p>0.05)$. Furthermore, there was no significant group by side interaction $(F(1,15)$ $=0.3, p>0.05)$ : i.e. the effects on pro-saccade 

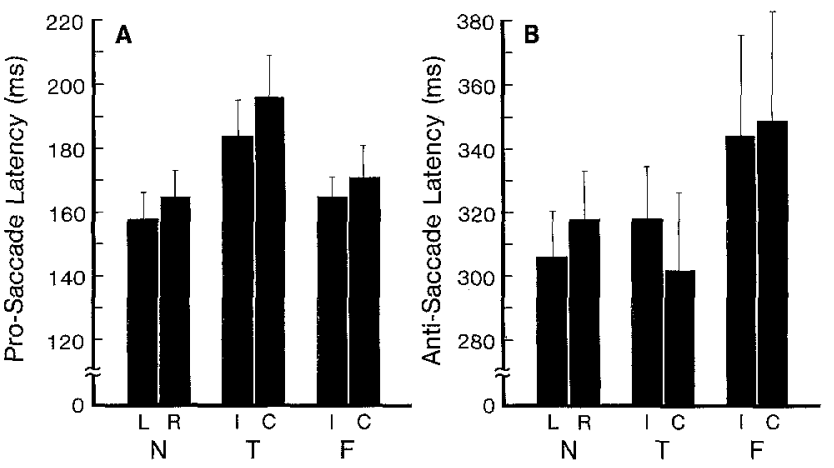

Fig. 3A and B. Saccade latency relative to the onset of the cue. The results in $\mathbf{A}$ and $\mathbf{B}$ are for the pro-saccade and anti-saccade tasks respectively. Only those anti-saccades that were not visually triggered and not preceded by a reflexive glance were included in the sample. The results for the normal, temporal and frontal groups are indicated by the letters $\mathrm{N}, \mathrm{T}$, and $\mathrm{F}$. Columns labelled $\mathrm{L}, \mathrm{R}$ refer to leftward and rightward saccades; I, C to the ipsilateral and contralateral sides relative to the lesion. Note the different scales on the ordinates of $\mathbf{A}$ and $\mathbf{B}$. The line segment above each bar indicates the standard error of the mean.

latency of ipsilateral or contralateral lesions are the same in temporal and frontal patients.

The lack of significance between the latencies of the differently directed pro-saccades suggests that to compare frontals, temporals and normals it is possible in each group to pool together all pro-saccades, independent of their directions. By doing this the group means and standard errors become respectively $168 \mathrm{~ms}(\mathrm{SE}=7.6), 190 \mathrm{~ms}(\mathrm{SE}=11.7)$, and
$162 \mathrm{~ms}(\mathrm{SE}=8.0)$ for frontals, temporals and normals, respectively. These means are statistically indistinguishable from each other $(\mathrm{F}(2,23)=2.75$, $p>0.05$ ).

The white bars in Fig. 4 show the percentage of trials in which the gap location was correctly identified. In the normals, responses to the left and right were the same. In the patient groups the symbol was identified equally well in movements to the ipsilateral and contralateral sides. As was found for latencies, the accuracy of the response was not side-dependent in those frontal patients that probably had damage of the FEF. Accordingly, in all groups the responses to the two sides can be pooled together to give means of $79 \%(\mathrm{SE}=8.5), 74 \%(\mathrm{SE}=9.8)$ and $80 \%(\mathrm{SE}=$ 8.7) for the frontals, temporals and normals respectively. There is no statistical difference between these values $(\mathrm{F}(2,23)=0.62, p>0.05)$. In summary, on the basis of latency and accuracy the frontals and temporals can be considered normal in the prosaccade task.

\section{Anti-saccade task}

Patterns of response. Figure 5 shows a group of responses made by a typical normal subject when the cue appeared on the right, thereby requiring a saccade to the left. Part A of the figure shows correct responses in which no saccades were made to the cue. The average latency of this subject's anti-saccades

Table 2. Latencies (ms) of pro-saccades and anti-saccades ${ }^{b}$ : normals vs "two-weeks post-op" patients

\begin{tabular}{|c|c|c|c|c|c|c|c|c|c|c|}
\hline \multirow{2}{*}{$\begin{array}{l}\text { Type of } \\
\text { movement }\end{array}$} & \multirow{2}{*}{$\begin{array}{l}\text { Direction } \\
\text { of saccade }\end{array}$} & \multirow[t]{2}{*}{ Normals } & \multicolumn{8}{|c|}{ Temporals } \\
\hline & & & BB & JG & JD & RT & $\mathrm{RP}$ & FW & $\mathrm{JB}$ & Mean \\
\hline Pro-saccades & Ipsi & 162 & 192 & 162 & 194 & 155 & 239 & 161 & 184 & $184 \pm 29$ \\
\hline$\left(\Delta \mathrm{T}^{\mathrm{c}}=300 \mathrm{~ms}\right)$ & contra & \pm 24 & 205 & 164 & 195 & 170 & 241 & 157 & 239 & $196 \pm 35$ \\
\hline Anti-saccades & Ipsi & 312 & 336 & 370 & 278 & 261 & 349 & 282 & 350 & $318 \pm 43$ \\
\hline$(\Delta \mathrm{T}=400 \mathrm{~ms})$ & contra & \pm 43 & 406 & 373 & 271 & 230 & 263 & 267 & 304 & $302 \pm 64$ \\
\hline
\end{tabular}

\begin{tabular}{lllllllllllllll}
\hline & 110 \\
\hline & & YG & RM & SK & EK & LG & SB & JH & JR & JF & CH & Mean \\
Pro-saccades & Ipsi & 187 & 190 & 140 & 183 & 169 & 142 & 173 & 149 & 143 & 174 & $165 \pm 20$ & 171 \\
$(\Delta \mathrm{T}=300 \mathrm{~ms})$ & contra & 190 & 180 & 161 & 180 & 164 & 143 & 179 & 131 & 140 & 241 & $17 \pm 32$ & \\
\hline Anti-saccades & Ipsi & VTe & VT & 302 & VT & VT & 359 & 215 & 357 & 411 & 414 & $343 \pm 75$ \\
$(\Delta \mathrm{T}=400 \mathrm{~ms})$ & contra & & & 328 & & & 350 & 216 & 415 & 344 & 445 & $349 \pm 79$ \\
\hline
\end{tabular}

\footnotetext{
a Movements which followed the onset of the symbol by more than $100 \mathrm{~ms}$ are not included in the means. Such saccades were assumed to be visually triggered (see text). Means and standard deviations given

b The anti-saccades considered here are those that are not preceded by a reflexive glance

"Latencies are for the "difficult" pro- and anti-saccade tasks in which the cue-symbol time interval $\triangle T=300 \mathrm{~ms}$ and $400 \mathrm{~ms}$ respectively

"Direction is relative to the side of the lesion. An "Ipsi" saccade is directed towards the lesioned hemisphere

e VT: all anti-saccades were visually triggered
} 


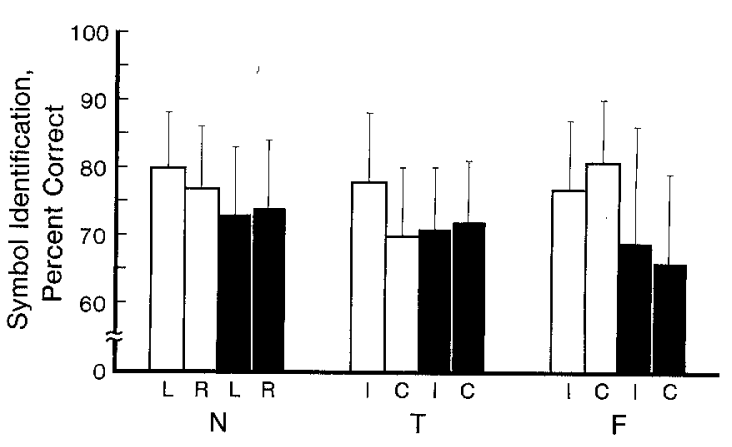

Fig. 4. Accuracy in correctly identifying the location of the gap. White and black bars refer to the pro-saccade and anti-saccade tasks respectively. See text and Fig. 3 for other details

was $320(\mathrm{SD}=11) \mathrm{ms}$. As shown on the time scale below the traces the symbol appeared $400 \mathrm{~ms}$ after the onset of the cue and therefore on the average the eye was at the required final position $80 \mathrm{~ms}$ before the symbol was presented. The check-marks on the left show that the gap's location was correctly identified on 20 of the 28 trials. Figure 5B shows incorrect responses in which the subject looked at the cue. These error responses have been arranged according to of the latency of the first saccade. Note that in most of these trials the wrong saccade was corrected by an anti-saccade, made across the blank screen, which attained the required location just before the symbol appeared, thereby permitting a correct identification on 5 of the 11 trials. These corrective "antisaccades" were approximately twice the amplitude of the initial cue offset.

Figure 6 shows anti-saccade trials made by a frontal patient (YG) who performed very badly in this task. The striking deficit in this and many other frontals was the difficulty in suppressing a disallowed glance at the cue. For convenience, hereafter, we will frequently refer to these disallowed saccades towards the cue as reflexive glances (Hess et al. 1946). When the cue was contralateral to the lesioned hemisphere (Fig. 6A) this patient made reflexive glances in $68 \%$ of the trials compared to errors in $76 \%$ of trials when the cue was presented on the ipsilateral side (Fig. 6B). As will be reemphasized below this strong bilateral deficit was present in many frontal patients even though their lesions were restricted to one hemisphere.

Even the so-called "correct" movements shown in Fig. 6C and D were different from the normal response. In the trials the subject correctly suppressed the disallowed glances, but the anti-saccades consistently lagged the onset of the symbol by a latency of about $100 \mathrm{~ms}$. Again this deficit was bilateral. Recall that antisaccades generated by nor-

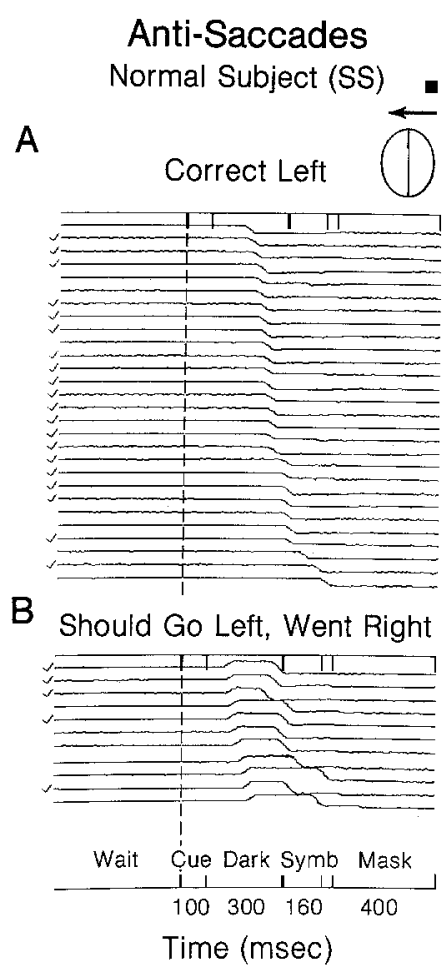

Fig. 5A and B. Anti-saccade task. Examples of saccadic eye movement responses generated by a normal subject. The inset at the top right shows schematically a top view of a head with the cue, represented by a dark square appearing on the subject's right. The correct anti-saccades are movements to the left shown by the downward going position changes in the eye movement traces of A. In $\mathbf{B}$ there is shown the incorrect responses in which the subject first made a rightward reflexive-glance to the cue and.then, in most trials, quickly corrected with another saccade that was generated before the symbol appeared, in time to identify correctly the symbol. See Fig. 2 for more details

mals usually were made before the symbol appeared. Additional results strongly suggest that these movements in YG were visually triggered by the appearance of the symbol. Indeed when the experimental conditions were kept constant except that the time between the cue and symbol was increased by $100 \mathrm{~ms}$ (Fig. 7A) the latency of the anti-saccades increased correspondingly and still lagged the onset of the symbol by a minimum of about $100 \mathrm{~ms}$. The striking feature of such responses was that saccades were visually triggered at latencies much shorter than those of this subject's pro-saccades $(100 \mathrm{~ms}$ vs $188 \mathrm{~ms}$ ). It is as if the subject's visuo-motor system had performed many of the computations necessary to move the eyes but simply could not trigger the required saccade.

This difficulty in generating anti-saccades that were not triggered by the appearance of the symbol was also apparent in YG's incorrect responses shown in Figs. $6 \mathrm{~A}$ and $\mathrm{B}$. When the cue was contralateral to 
Anti-Saccades

Frontal Patient (YG)
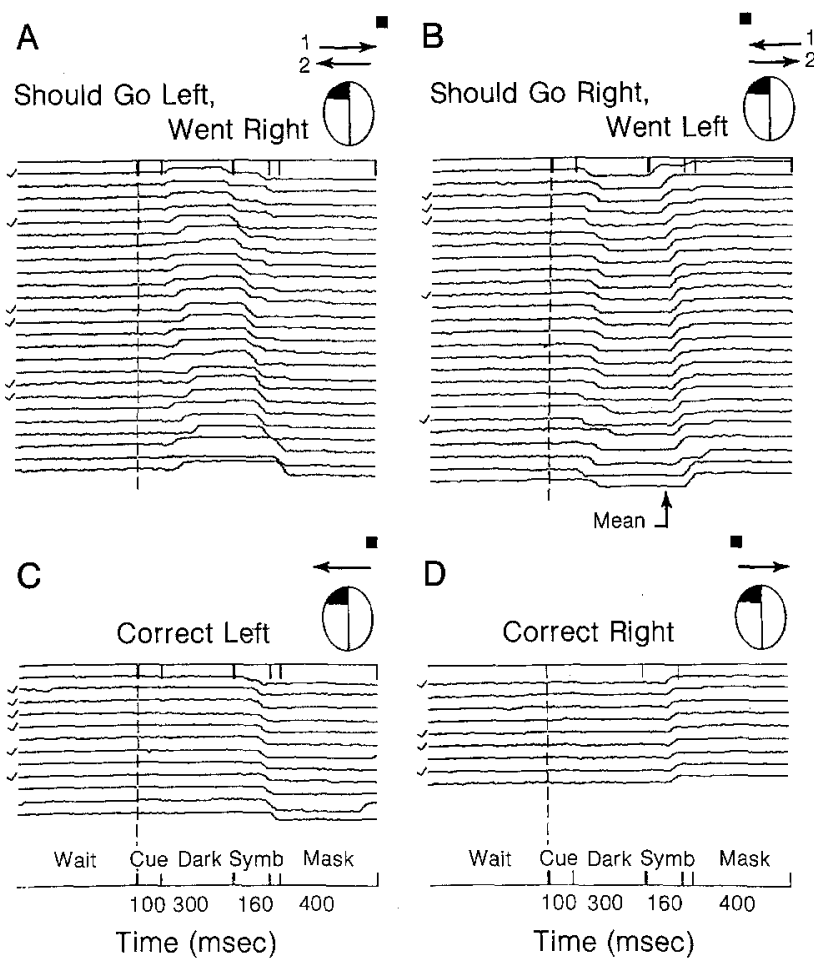

Fig. 6A-D. Anti-saccade task. Responses illustrating the severe deficits of frontal patient YG. The inset above each series of traces shows schematically a top view of YG with a lesion in the left frontal lobe. The position of the cue is indicated by the small dark square. The arrow(s) below the square indicate the direction(s) of the eye movement responses. They are numbered according to their order of appearance. All eye movement traces have been aligned by the computer on the basis of increasing latency of the first correctly directed saccade. A Incorrect responses: subject first makes rightward saccade to the cue (first upward deflection of eye movement traces corresponding to top arrow of inset) and then corrects with a saccade directed away from the cue, to the left in the anti-saccade direction. In the top 11 traces the first corrective (leftward) anti-saccade approximatly recenters the eye and is too early to have been visually triggered by the symbol. When the symbol appears there is a further corrective saccade which brings the eye on target. In the bottom 8 traces the first corrective leftward saccade lags the symbol by about $100 \mathrm{~ms}$ and could have been visually triggered (see below). The vertical arrow below the traces indicates the mean latency of this first corrective antisaccade. B Incorrect responses: subject should go right but first went left. In this case the first corrective (rightward) anti-saccade, which is organized by the damaged hemisphere, lags the symbol more frequently than the first corrective leftward saccades shown in A. C Correct responses: subject correctly suppressed a reflexive glance towards the cue and generates an appropriately directed leftward anti-saccade. Howeve, this saccade consistently lags the symbol by about $100 \mathrm{~ms}$. Based on the data of Fig. 7, it is concluded that these movements are visually triggered at an unusually short latency. D Correct responses: subject correctly suppresses reflexive glance towards the cue and generates an appropriately directed rightward anti-saccade. Same comments as for C. See Figs. 2 and 5 for additional details

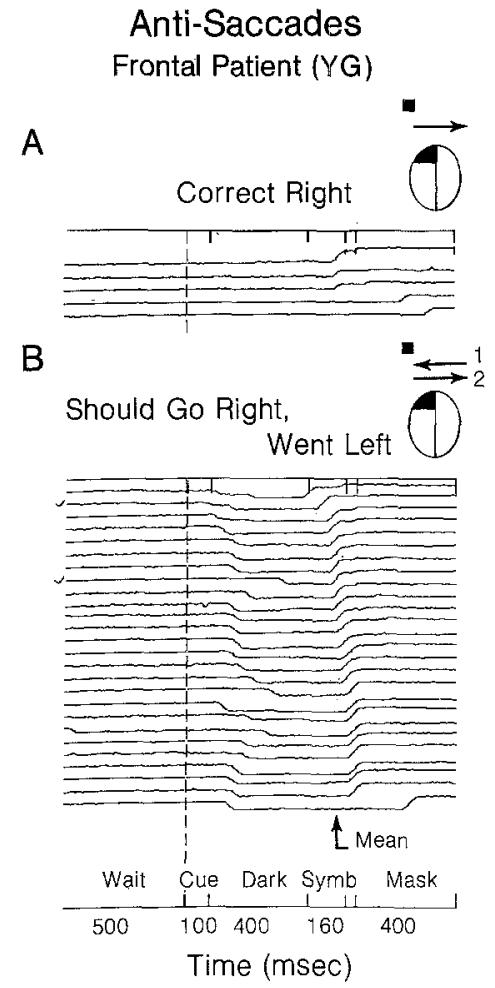

Fig. 7A and B. Anti-saccade task. Same patient and conditions as those shown in Fig. 6 except that the cue-symbol time interval has been increased to $500 \mathrm{~ms}$. A Correct responses: subject correctly suppresses a leftward reflexive gaze towards the cue and generates the appropriate rightward anti-saccade. However, these responses, like those in Fig. 6D, always lag the appearance of the symbol by $100 \mathrm{~ms}$ or longer. B Incorrect responses: subject should go right but first went left. Note that after the reflexive glance the corrective anti-saccade that is generated by the lesioned hemisphere nearly always lags the symbol in spite of there being more time. The vertical arrow below the traces indicates the mean latency of this corrective movement. These observations, in conjunction with Fig. 6, suggest that YG computes the goal of his anti-saccade but has difficulty triggering the movement from an internal source. See text and Figs. 2 and 5 for further details

the lesion (Fig. 6A), the subject, following the incorrect glance, frequently (in 10 of the 25 trials in the display) either recentered the eyes or generated an anti-saccade that was too small and he could not generate a saccade to the symbol until about $100 \mathrm{~ms}$ or more after it appeared. This difficulty was more striking when the cue was ipsilateral to the damaged side (Fig. 6B) such that, presumably, the antisaccade was to be generated by the damaged hemisphere. In this condition there were no recentering movements and the correctly directed rightward saccades lagged the symbol by $100 \mathrm{~ms}$ or more in $70 \%$ of the trials. That these tended to be short latency visually triggered anti-saccades is illustrated in Fig. 7B which shows results obtained when the time between cue and symbol was increased by 


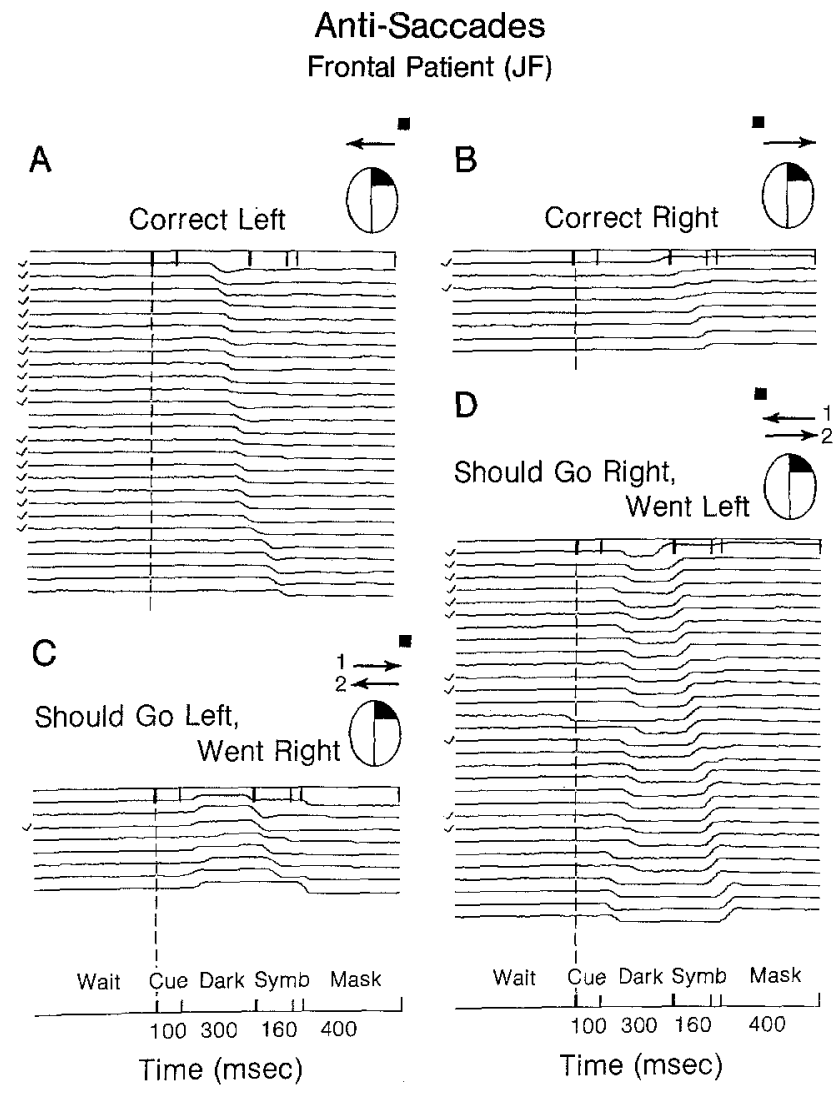

Fig. 8A-D. Anti-saccade task. Responses showing severe unilateral deficit in frontal patient JF. $A$ and $C$ When the cue is ipsilateral to the lesioned side, JF can easily suppress a reflexive glance and can generate, with his lesioned hemisphere, an antisaccade that in most trials attains the target zone in time for the correct identification of the symbol. B and $\mathbf{D}$ When the cue is contralateral to the lesioned side, JF has difficulty in suppressing a reflexive glance. The anti-saccades driven by the lesioned hemisphere were, in this patient, faster than those generated by the good hemisphere. This was not a typical finding (Table 1 and text). See Figs. 2 and 5 for further details

$100 \mathrm{~ms}$. It is observed that, following the disallowed glance, the first corrective anti-saccades nearly always lagged the symbol in spite of the greater time available for performing the task, and their average latency was considerably greater than that of the first corrective anti-saccades shown in Fig. $6 \mathrm{~B}$ (See arrows indicating mean latency in Figs. 6B and 7B).

Not all frontal patients showed YG's striking bilateral tendency to make reflexive glances. In some (SB, JH, JR, JF) the deficit was strongest when the cue was presented contralateral to the damaged hemisphere. We will illustrate these responses with the results of JF from whom we were able to gather considerably more data than for the others (see also Fig. 11). Note that even though JF had both frontal and temporal lesions he showed the same deficiencies as purely frontal patients. Figure 8 shows results obtained from JF tested 2 weeks post-operatively in the same, "difficult", anti-saccade task as used for patient YG. When the cue was ipsilateral to the damaged hemisphere, $\mathrm{JF}$ was normal in his ability to generate anti-saccades (Fig. 8A and C). However, when the cue was on the contralateral side (Fig. 8B and $D$ ) there was a radical change in performance and the patient had great difficulty in suppressing the disallowed glance. In many trials where this glance occurred, the subject was capable of repairing the error by generating correctly directed anti-saccades whose timing showed that they could not have been visually triggered by the appearance of the symbol. In this subject, the rightward anti-saccades driven by the good hemisphere, (Fig. 8B) tended to have a longer latency than the anti-saccades driven by the lesioned hemisphere (Fig. 8A). This was, however, not a significant characteristic in either frontal or temporal patients (see Table 1 and next sections).

Frequency of reflexive glances. A total of 10 frontal subjects were tested 2 weeks post-operatively and Fig. 9 shows the percentage of their responses in which a disallowed glance was made when they were tested in the "difficult" anti-saccade run (in which the onset of the symbol lagged that of the cue, $\triangle T$, by $400 \mathrm{~ms}$ ). The hatched bars indicate those trials in which the cue was contralateral to the lesion. The dotted bars represent the opposite situation. The approximate extent of cortical excisions, based on drawings made by the surgeon, are shown in black on each schematic brain diagram along the bar graph. Comparing the bilaterally affected patients with the remaining frontals suggests that the strongest deficit is associated with dorsolateral lesions just anterior to the motor strip although patient $\mathrm{CH}$ was a striking exception to this rule. The relationship between the location of a lesion and the severity of the associated deficit will be considered in the Discussion.

Figure 10 compares the mean of the values in Fig. 9 with the corresponding means in the other groups of subjects. The tendency of frontal patients to make "reflexive" glances and/or visually triggered anti-saccades contrasts markedly with observations made in temporals and normals. For the nine normals, the mean proportion of trials exhibiting reflexive glances to the left and right were $20.2 \%$ ( $\mathrm{SE}=$ $6.3)$ and $21.7 \%(\mathrm{SE}=7.2)$ respectively. These values are not significantly different and consequently the leftward and rightward responses for each subject have been pooled to yield an overall mean error for normals of $19.8 \%$ ( $\mathrm{SE}=5.4)$. For the frontals the mean percent errors in direction when the cue was ipsilateral and contralateral to the lesion were $51.2 \%$ 
Anti-Saccades by Frontal Patients Tested Two Weeks Post-Operatively

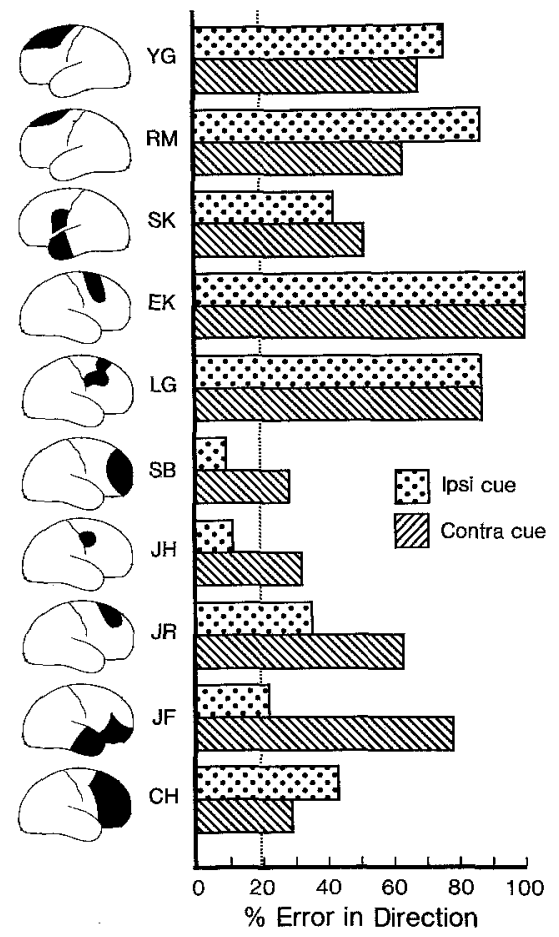

Fig. 9. Relative number of reflexive glances made in the antisaccade task by those frontal patients tested 2 weeks after surgery. The height of each dotted bar represents the total number of reflexive glances divided by the total number of trials when the cue was shown on the side ipsilateral to the lesioned hemisphere. The hatched bars represent analogous data obtained with a contralateral cue position. The schematic brains, adjacent to each patient's identification, show the extent of the cortical excision as drawn by the surgeon at the time of operation. The horizontal dotted line shows the error rate of the temporal patients

$(\mathrm{SE}=10.7)$ and $59.9 \%(\mathrm{SE}=7.9)$ respectively. The corresponding values in the temporals were $18.9 \%$ $(\mathrm{SE}=5.1)$ and $19.5 \%(\mathrm{SE}=4.3)$ respectively. An analysis of variance, similar to that used for analyzing pro-saccades, was used to compare the performance of the temporals and frontals. The results show a highly significant difference $(\mathrm{F}(1,15)=10.64, p<$ 0.01 ) between the means of errors in these two patient groups. However, the population means of errors to ipsilateral and contralateral cue positions were not significantly different $(\mathrm{F}(1,15)=2.61, p>$ $0.05)$. Furthermore, there was no significant $(F(1,15)$ $=1.49, p>0.05)$ side-of-cue by subject interaction: i.e. the error rate in frontals was not affected significantly differently than for temporals when the cue appeared contralaterally compared to ipsilaterally. Since the effects of side-of-cue were not significant, the result for either side were pooled in each patient to yield group means of $19.2 \%(\mathrm{SE}=$

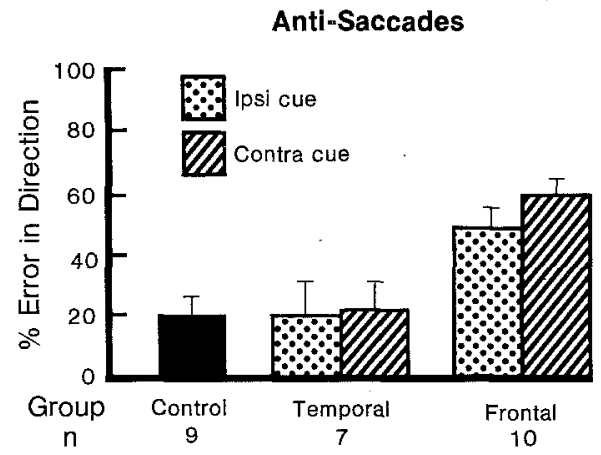

Fig. 10. Pooled data showing tendency of each group to make reflexive glances. The patients were studied two weeks postoperatively. The height of the dotted bars represents the mean percent error in direction when the cue was shown ipsilateral to the lesioned hemisphere. The hatched bars represent data obtained with a contralateral cue position. The data for the control gorup was obtained by first pooling together each subject's responses for left and right cue positions and then obtaining the average of these pooled values

4.6) and 55.8\% ( $\mathrm{SE}=8.9)$ in the temporals and frontals respectively compared to the value $27.1 \%$ ( $\mathrm{SE}=5.4$ ) obtained in the normals. A one-way analysis of variance showed that only the frontals differed significantly from the other groups $(F(2,23)$ $=9.31, p<0.01$ ).

Latencies. The more mildly affected patients (excluding YG, RM, EK and LG) had either weak bilateral deficits or unilateral deficits of varying intensity (Fig. 9). They were, with various degrees of success, able to suppress the disallowed glance and to generate a true anti-saccade whose onset preceded that of the symbol. It is of interest to compare the latencies of these true anti-saccades in the mildly affected frontals with those obtained in the normals and temporals to determine, for example, if there are significant differences between the latencies of movements generated by the intact and damaged hemispheres. These results are shown in Table 2 for the task in which $\triangle T=400 \mathrm{~ms}$. The results labelled "ipsi" and "contra" refer to anti-saccades directed towards the ipsilateral and contralateral sides respectively. In calculating the latencies all values greater than 500 ms were excluded since saccades with such latencies occur more than $100 \mathrm{~ms}$ after symbol onset and therefore are most likely visually triggered. This fact was verified by plotting for each subject a distribution of the number of saccades versus latency and noting that there were two peaks to the distribution as shown by the insets of Fig. 11 (to be considered below). The mean latencies are plotted in Fig. 3B. In the normals there was no significant left-right asymmetry in latency. This is in agreement with Hallett 

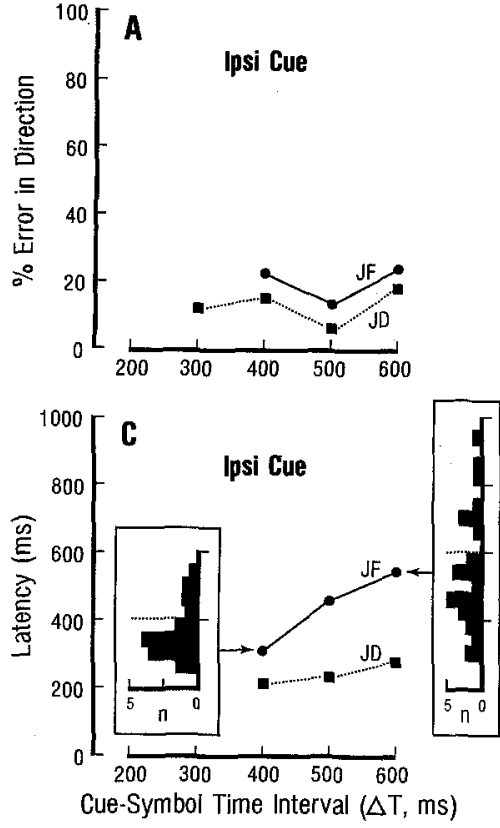
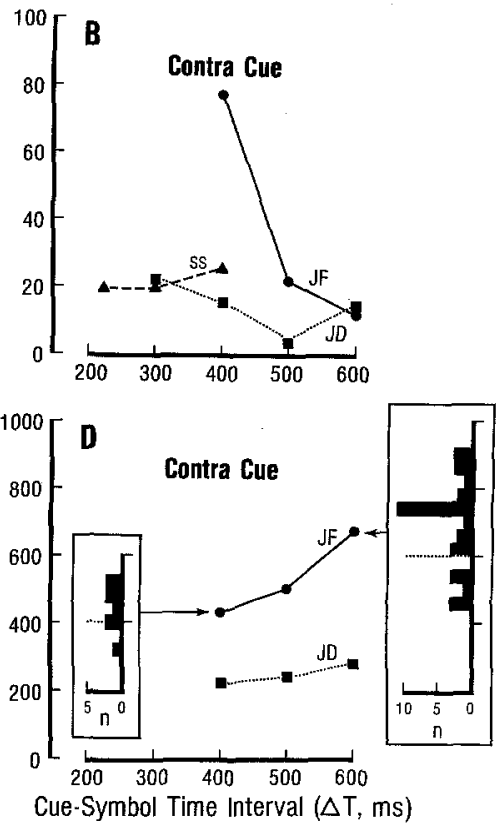

Fig. 11A-D. Influence of changing the cue-symbol time interval $(\Delta T)$ on the frequency of reflexive glances and the latency of anti-saccades. $\mathbf{A}$ and $\mathbf{B}$ the frequency of reflexive glances versus $\Delta \mathrm{T}$ for cue positions that are ipsilateral and contralateral, respectively, to the lesion. $\mathbf{C}$ and $\mathbf{D}$ the latency of anti-saccade, that are unaccompanied by reflexive glances, versus $\Delta T$ for ipsilateral and contralateral cue positions respectively. Insets are histograms, with $40 \mathrm{~ms}$ bin widths, that show the number ( $\mathbf{n}$ ) of anti-saccades having latencies appropriate to each bin for frontal patient JF. The dashed line across each inset indicates the time of onset of the symbol. The filled circles indicate the mean latency of those anti-saccades whose onset time did not extend $100 \mathrm{~ms}$ or more beyond that of the symbol. See text for further details. Filled squares: temporal patient JD; triangles, normal SS. The data for SS are plotted in $\mathbf{B}$ for convenience since the distinction between "ipsi" and "contra" is meaningless for a normal subject
(1978) and Hallett and Adams (1980). The mildly affected frontals tended to have longer latencies than the other groups but this difference was not significant. Indeed analysis of variance showed that: (1) the mean latencies of each of the temporal and frontal groups did not differ significantly $(\mathrm{F}(1,11)=0.86$, $p>0.5)$; (2) there was no significant difference between the population means for anti-saccades directed ipsilaterally and contralaterally $(\mathrm{F}(1,11)=0.56$, $p>0.05$ ); and (3) the effects on anti-saccade latency of ipsilateral or contralateral lesions are similar in the temporal and frontal patients $(\mathrm{F}(1,11)=0.11, p>$ 0.05 ). It is therefore possible to pool together, in each group, the differently directed anti-saccades. This yields group means of $312 \mathrm{~ms}(\mathrm{SE}=14.3), 310$ $\mathrm{ms}(\mathrm{SE}=20.0)$, and $346 \mathrm{~ms}(\mathrm{SE}=30.3)$ in the normal, temporal and mildly affected frontal patients. Although these frontals have a longer latency, the differences are not statistically significant $(\mathrm{F}(2,19)=0.91, p>0.05)$.

Hallett and Adams (1980) have shown for normal subjects, that the mean pro-saccade latency $(\mathrm{N})$ and anti-saccade latency (A) are related, among subjects, by the equation $\mathrm{A}=2 \mathrm{~N}-144.5(\mathrm{r}=0.98)$. In our anti-saccade task, which differed primarily from Hallett's paradigm in that our subjects, not his, were required to identify a symbol, none of the groups conformed to this or any other significant relationship. The linear regression equation, linking the two latencies in our groups were:

Normals $\quad \mathrm{A}=0.59 \mathrm{~N}+216.5(\mathrm{r}=0.29)$

Temporals $\mathrm{A}=0.31 \mathrm{~N}+250.0(\mathrm{r}=0.20)$

Frontals $\quad \mathrm{A}=0.24 \mathrm{~N}+302.4(\mathrm{r}=0.09)$
Table 3. Difference ${ }^{a}$ between latencies (in $\mathrm{ms}$ ) of anti-saccades that are and are not preceded by a reflexive glance

\begin{tabular}{lllllllll}
\hline $\begin{array}{l}\text { Direction of } \\
\text { anti-saccade }\end{array}$ & Normals & \multicolumn{6}{c}{ Frontals $^{\mathrm{b}}$} \\
\hline $\begin{array}{l}\text { Ipsi (driven } \\
\text { by good hemi- } \\
\text { sphere) }\end{array}$ & SK & SB & JH & JR & JF & Mean \\
$\begin{array}{l}\text { Contra (driven } \\
\text { by bad hemi- } \\
\text { sphere) }\end{array}$ & 41 & 54 & 84 & 55 & 0 & $46.8 \pm 30.5$ \\
\hline
\end{tabular}

a Numbers in the table indicate in general that anti-saccades preceded by a reflexive glance had a longer latency. Means and standard deviations are given

b Those patients omitted from the table had anti-saccades (either with or without reflexive glances) that were visually triggered

Hallett and Adams (1980) have further speculated about the various processes and related delays that are implicated in the generation of the antisaccade task. In their view there is first established, in one hemisphere, a sequence of processes related to the generation of a saccade towards the cue but, after a decisional element, these processes are cancelled. A switch of function is made from one hemisphere to another, and a new sequence of partly similar processes undertaken. In this scheme it is possible that the existence of a reflexive glance reflects only a failure to cancel and suggests that the latency of antisaccades might be essentially independent of whether or not the disallowed glance has occurred. Thus, the cue could set up two independent and concurrent 
processes, each leading to a saccade driven by a separate hemisphere. We have compared the latencies of true anti-saccades (movements unaccompanied by a reflexive glance) with those of corrective anti-saccades that follow reflexive glances and bring the eye to its required goal position without being visually triggered by the symbol. The results are shown in Table 3. The true anti-saccades always had a shorter latency, and the time differences between the two types of anti-movements was on the average $60 \mathrm{~ms}$ in normals (no laterality effect) and $43 \mathrm{~ms}$ in frontals (mean for 'ipsi' and 'contra' saccades). Thus the latency of anti-saccades is not independent of the occurrence of a reflexive glance.

\section{Accuracy of responses}

In the present experiments the percent of all trials in which the symbol was correctly identified was taken as a measure of the adequacy in both timing and amplitude of the saccades that brought the eyes to a required goal position. (This criterion appeared adequate for amplitude since corrective saccades were frequently seen in those trials where an incorrect reply was made and yet sufficient time for identification was available). The mean percentage for true anti-saccades (i.e. those that are not visually triggered and which are not preceded by a reflexive glance, Table 2) in each group are shown by the dark bars in Fig. 4. There are no statistically significant side differences in the groups. The pooled means are $74 \%(\mathrm{SE}=8.4), 72 \%(\mathrm{SE}=8.7)$, and $67.5 \%(\mathrm{SE}=$ 12.7) for the normal, temporal and frontal groups respectively. The differences between these means are not statistically significant $(\mathrm{F}(2,19)=0.66$, $p>0.05$ ).

\section{Effect of changing task difficulty}

The results presented in Fig. 9 and summarized in Fig. 10, were obtained in the "difficult" anti-saccade runs in which the cue-symbol time interval $\Delta \mathrm{T}$ was $400 \mathrm{~ms}$. An important additional feature of our results was that in general the frequency of reflexive glances in frontals diminished when the task was made less demanding. In the present experiments the task could be simplified in two ways: either by increasing $\Delta \mathrm{T}$ or by not presenting the symbol. The latter situation was equivalent to having $\Delta \mathrm{T}=\infty$ but with the additional important feature that subjects knew there would be no symbol to identify.

Figure 11 presents data obtained when $\Delta \mathrm{T}$ was varied. Parts $A$ and $B$ of the figure show, for ipsilateral and contralateral cue positions respec- tively, the frequency of reflexive glances made by frontal patient JR, temporal patient JD, and normal subject SS, when the time of onset of the symbol relative to that of the cue was varied. Parts $\mathrm{C}$ and $\mathrm{D}$ show for patients JF and JD the latency of antisaccades (when there were no reflexive glances) for the corresponding time intervals. The points at $\Delta \mathrm{T}=$ $400 \mathrm{~ms}$ for JF correspond to the data shown in Fig. 7.

Figure $11 \mathrm{~A}$ and $\mathrm{B}$ show that JF's error rate was about normal when the task was "easy" $(\Delta T=600$ $\mathrm{ms})$. However, when JF was forced to try harder his performance changed radically and at $\Delta \mathrm{T}=400 \mathrm{~ms}$ he developed a strong unilateral tendency to look at the cue when it was presented on the side contralateral but not ipsilateral to the lesion. Note that this deterioration in performance in the difficult runs is counter to the expectations of an improvement due to practice (Hallett 1978; Hallett and Adams 1980) since in an experimental session the "difficult" task was always run after the "easy" task (see Methods). The performance of the temporal patient JD showed little dependence on $\Delta \mathrm{T}$ for either ipsilateral or contralateral cue positions. Furthermore, the normal subject (SS) underwent a very demanding session in which $\Delta \mathrm{T}$ was $220 \mathrm{~ms}$, thereby providing a total time to the symbol's disappearance of only $370 \mathrm{~ms}$. The average of SS's responses to the left and right sides are given in Fig. 11B and show that there was no tendency to increase the number of reflexive glances as the task difficulty increased.

Figure $11 C$ and D show for patients JF and JD, in the same experimental conditions as in Fig. 11A and $B$, how anti-saccade latency varied with $\Delta \mathrm{T}$. For temporal patient JD there was a small decrease in latency as $\Delta \mathrm{T}$ decreased. For JF the latency changed more and with the cue either ipsilateral or contralateral the average latency in each case decreased by about $200 \mathrm{~ms}$ as $\Delta \mathrm{T}$ decreased by $200 \mathrm{~ms}$. The shorter latencies could simply have been due to an increase in the number of saccades that were visually triggered by the earlier appearance of the cue when $\Delta T$ was decreased. To verify this, there is plotted in each inset of Fig. $11 \mathrm{C}$ and D, a histogram, with $40 \mathrm{~ms}$ bins, showing the number (n) of anti-saccades at each latency. The dashed lines at latencies of either $400 \mathrm{~ms}$ or $600 \mathrm{~ms}$ indicate the time of appearance of the symbol. It can be seen in each histogram that the distribution of anti-saccade latencies is such as to favour two groups; one preceding the symbol, the other lagging by latencies ranging from $80-140 \mathrm{~ms}$. Based on the data of Figs. 6 and 7, it is probable that the latter group is composed of saccades that were visually triggered.

The data shown for frontal patient JF was characteristic of all frontal patients except YG, RM,EK and 


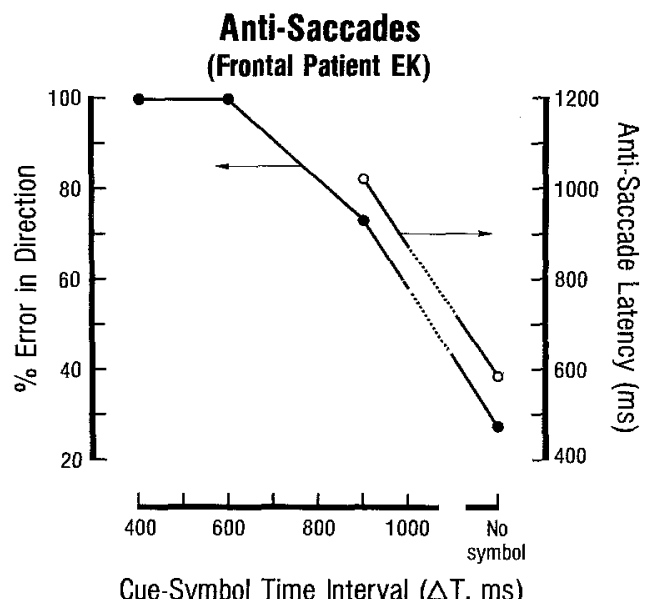

Fig. 12. Influence of changing the cue-symbol time interval $(\Delta T)$ on frontal patient EK's tendency to make reflexive glances and on his anti-saccade latencies. Left ordinate and filled circles give percent of total trials (average of the data obtained with the cue in both the ipsilateral and contralateral positions) in which a reflexive glance occurred. Right ordinate and open circles give the latency of anti-saccades in those trials in which no reflexive glance occurred. There are no calculable latencies at $\Delta T=400$ and $600 \mathrm{~ms}$ where reflexive glances occurred in all trials

LG. For $\Delta \mathrm{T}=600 \mathrm{~ms}$ these latter patients still had great difficulty in suppressing reflexive glances. We were able to test one of them (EK) when the task was further simplified by either increasing $\Delta \mathrm{T}$ to $900 \mathrm{~ms}$, or by not presenting the symbol at all. These data, averaged for ipsilateral and contralateral cue presentations (which yielded similar results), are shown in Fig. 12. At $\Delta \mathrm{T}=900 \mathrm{~ms}$ EK's error rate dropped from 100 to $73 \%$ and the average latency of those anti-saccades that were not preceded by a disallowed glance was $1020 \mathrm{~ms}$. This latency shows that these movements, on the average, occurred after the symbol and further suggests that most were visually triggered with a mean latency of $120 \mathrm{~ms}$. Interestingly, when no symbol was presented, thereby eliminating the need to identify the gap's location and giving EK "limitless" time to perform the antisaccade task, the error rate dropped to a normal value and the latency decreased to an average of $590 \mathrm{~ms}$. The task in which no symbol was presented was also given to three other frontal patients (SB, JR of Fig. 9 and MS of Fig. 13). In all cases the error rate decreased in relation to their performance at $\Delta \mathrm{T}=600 \mathrm{~ms}$ and the anti-saccade latency decreased.

The latency of reflexive glances was also affected by changing $\Delta \mathrm{T}$. For $\mathrm{JF}$ the average latencies of reflexive glances to the ipsilateral and contalateral sides changed considerably and were $145 \mathrm{~ms}, 171 \mathrm{~ms}$ and $270 \mathrm{~ms}$ when $\Delta \mathrm{T}$ was $300 \mathrm{~ms}, 500 \mathrm{~ms}$ and $600 \mathrm{~ms}$ respectively. For EK the mean latencies were $191 \mathrm{~ms}$

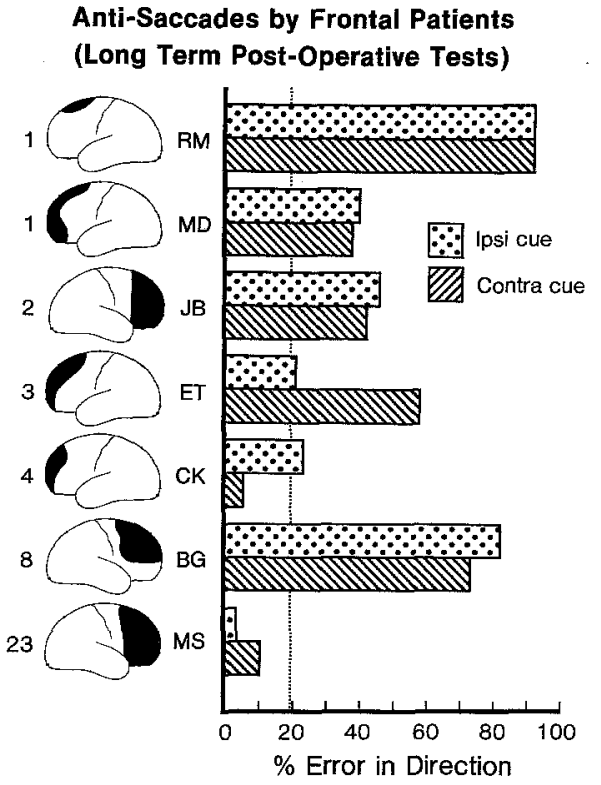

Fig. 13. Relative number of reflexive glances made in the antisaccade task by those frontal patients tested one year or more after surgery. See Fig. 9 for other details. Number near each brain map indicates number of post-operative years

and $246 \mathrm{~ms}$ when $\Delta \mathrm{T}$ was $600 \mathrm{~ms}$ and $800 \mathrm{~ms}$ respectively. When no symbol was presented the latencies remained at the value they had at $\Delta \mathrm{T}=$ $600 \mathrm{~ms}$.

In summary, when the task difficulty was reduced by increasing $\Delta \mathrm{T}$ but leaving the requirements to identify the gap's location, the frequency of reflexive glances in frontals (not temporals and normals) decreased and the latency of reflexive glances and anti-saccade increased. When no symbol was shown the directional error rate decreased further but now the anti-saccade latency decreased.

\section{Effect of post-operative time}

It is generally agreed upon that the short term effects of frontal lobe and FEF ablation take approximately two-weeks to subside (Bianchi 1895; Kennard and Ectors 1938; Welch and Stuteville 1958; Schiller et al. 1980; Crowne et al. 1981). Accordingly, the patients whose data are summarized in Figs. 3, 9 and 10 were all studied at about this post-operative time when they were still at the hospital. To determine whether the deficits described above are still present on the very long term, a number of patients with postoperative times varying between 1 and 23 years were tested. Their results are presented in Fig. 13 where the number under each brain map represents the respective approximate post-operative time in years. 
Note also that patient RM is the same one as in Fig. 9.

The results for the majority of patients are similar to those of Fig. 9 and again suggest that dorsolateral lesions induced an abnormally high number of "reflexive" glances although patient MS like CK previously, was an exception to this rule.

\section{Discussion}

The present study has demonstrated that frontal lobe lesions in man can produce a severe and multifaceted deficit in a simple task that requires a subject to generate a saccadic eye movement away from a stimulus (the cue) presented in his peripheral vision. The first notable feature of this task is that it requires the subject to cancel the tendency to look at the cue. That this is a strong tendency, appropriately called the "visual grasp reflex" (Hess et al. 1946), is illustrated by the relatively high number of trials (mean $=20 \%$ ) in which normal subjects looked at the cue.

The following observations indicate that nonspecific influences, such as a general disturbance of CNS function following surgical trauma, are not relevant to the strong deficit seen in the frontal group: (1) Temporal patients performed as well as normals on the anti-saccade task. (2) Frontal patients perform the pro-saccade task normally. (3) Many frontal patients were normal on the IQ, CS and WF tests but abnormal on the anti-saccade task. Furthermore, the similarity between the frontal patients studied one year or more after their lesion and those studied two weeks post-operatively suggests that post-operative time is not a critical element in the observed deficits.

\section{Effect of lesion location}

Five frontal patients (YG, RM, EK, LG and BG) had strikingly strong bilateral deficits which were the greatest in patient EK who could never suppress a saccade to the cue unless the task was considerably simplified. These patients were also the only ones whose anti-saccades in the symbol identification task were always visually triggered, independent of whether or not the reflexive glance was suppressed, as exemplified by the responses shown in Figs. 6 and 7 . Four of these patients (YG, EK, LG and BG) had probable lesions of the FEF as suggested by either a comparison between the anatomical location of their lesion and the known FEF site (Penfield and Boldrey 1937; Rasmussen and Penfield 1948; Penfield and Rasmussen 1950; Penfield and Jasper 1954; Melamed and Larsen 1979) or, in the case of YG, by electrical stimulation of the cortex during surgery and noting those sites where eye movements were evoked. The strong bilateral deficits may have been caused by a reduced efficacy of the contralateral FEF due to an interruption of the homotypical commissural connections (Pandya and Vignolo 1971). Interestingly the lesions of these 4 patients also extended into the mesial side of the hemisphere and almost certainly encroached on the frontal supplementary motor area (SMA) which may also be implicated in the generation of saccades (Melamed and Larsen 1979). Patient RM was a possible exception to this rule. His lesion, which also extended onto the mesial wall, encroached on the SMA but may not have extended far enough on the lateral surface to encroach on the FEF. However, FEF involvement in this patient was quite possible due to the known large variations in the location of this structure (Melamed and Larsen 1979). The most notable exception to these generalizations was patient MS (Fig. 13) who had an almost total removal of a prefrontal lobe and yet exhibited a better than normal capability for cancelling the reflexive glances. This patient, however, was not quite normal in his ability to generate anti-saccades and this will be considered in more detail in the last section.

By comparison with those patients having combined dorsolateral and mesial lesions, other patients with lesions restricted to the frontal pole (SB, CK) or motor strip (JH) were essentially normal. Two other groups had either weak bilateral (SK, CH, MD, JB) or strong unilateral (JR, JF, ET) effects respectively. For these latter groups it is difficult to establish a clear link between lesion location and deficit. Comparing the results of JR, JF and ET leads to the generalization that in the anti-saccade task there are specific and non-specific effects of frontal lesions. Thus the ability to suppress the reflexive glance may require primarily the dorsolateral and possibly mesial areas but also in part may require the integrity of a large portion of the frontal lobe (see section "reflex cancellation" below). In concordance with this view, Fuster (1981), in his review of the role of the prefrontal cortex in motor control, concluded that abnormal distractability cannot be ascribed to any particular frontal locus. By comparison to the ability to suppress the disallowed glance the ability to generate anti-saccades may be more specifically related to the integrity of the FEF and SMA.

\section{Present observations versus past studies}

It has been reported that unilateral frontal lobe lesions, particularly in the dorsolateral region, pro- 
duce transient unilateral neglect in monkey (Kennard and Ectors 1938; Welch and Stuteville 1958; Latto and Cowey 1971a, b) and man (Heilman and Valenstein 1972). In the present study, frontal patients studied two weeks or more after their operation, certainly did not neglect the cue. (Any evidence of neglect in these surgical patients is generally gone 3-4 days after the operation; Rasmussen, personal communication). In the pro-saccade runs they generated an accurate saccade, with normal latency, to the goal position and they were normal in their ability to identify the symbol. Furthermore, in the anti-saccade runs they had difficulty in suppressing a disallowed glance at the cue.

There is another line of evidence that links frontal lobe damage to a constellation of symptoms reminiscent of our findings and called motor hyperactivity, excessive reactivity to stimuli, and abnormal distractability (see Fuster 1981 for review). Examples of this in the oculomotor system are reported by Jeannerod et al. (1968) and Jeannerod (1972) who observed that cats with frontal lobe lesions displayed perseverative visual tracking and suggested that such behavior results from the uncontrolled release of "simple" reflex-like responses. Holmes (1938) had observed similar reactions in frontal patients and had suggested that frontals were "confined by the fatality of a reflex". The tendency of our frontal patients to make reflexive glances at the cue is in striking agreement with such observations. Interestingly, an analogous impairment has been observed in the limb motor control system, where ablation of the premotor cortex in monkey (including the FEF) "impairs the capacity of the contralateral arm to reach around a transparent obstacle to a visible food reward and results in a tendency of the arm to reach straight to where the food is visible" (Moll and Kuypers 1977).

\section{Neurophysiological basis}

Between the two frontal structures - the SMA and FEF - that are thought to be implicated in oculomotor control, the greatest research efforts have been by far devoted to unravelling the role of the FEF. This structure and the SC are thought to be crucial to the genesis of saccadic eye movements (see Zee 1984 for review). Classically, the SC in man and monkey, being the homologue of the tectum in lower vertebrates, has been thought to mediate the "visual grasp reflex" (Hess et al. 1946; Schiller and Koerner 1971; Schiller and Stryker 1972). Indeed, the SC seems ideally structured to act as a visuomotor structure. It contains in its superficial layers, neurons that have visual receptive fields, and in its intermediate and deep layers, neurons that discharge preceding saccades to visual stimuli (see Wurtz and Albano 1980 for review). Nevertheless, following unilateral ablation of the SC in monkey there is only a minimal effect on the latency and accuracy of saccades made to visual stimuli in order to obtain a food reward (Albano et al. 1982). However, there is an important decrease in the frequency of saccades made to contralateral visual targets relative to that made to ipsilateral targets when such visually guided saccades are not rewarded in the behavioral paradigm (ibid). Therefore Albano et al. (1982) have suggested that monkeys with unilateral lesions of the SC are less distracted by stimuli presented to their contralateral field. (Recall that in the present results the frontal patients show more distractability). Similarly, in a visual search task, where the generation of saccades per se was not rewarded, Schiller et al. (1980) found that bilateral SC ablation reduced considerably the average saccade velocity, amplitude and frequency.

As a counterpart to the SC, the FEF has long been thought to mediate voluntary saccades but recent evidence suggests that it may be implicated primarily in the control of sense-triggered (e.g. visual) saccades (Goldberg and Bushnell 1981; Bruce and Goldberg 1985). Of particular relevance to the anti-saccade task is the observation that so-called "visuomovement" neurons respond best in relation to visually triggered saccades but do not require the visual target to be in the neuron's receptive field, i.e. "the critical signal for the frontal eye fields is not the retinal location of a target but the movement that the target will evoke" (Goldberg and Bruce 1981).

Interestingly, bilateral lesions of the monkey FEF yield no observable longterm eye movement deficits in the visual search task of Schiller et al. (1980). However, bilateral ablation of both the SC and FEF yields, in this task, deficits similar to but much stronger than those observed following bilateral lesions of only the SC.

The observations have suggested that the FEF and SC act as two parallel and interacting systems in the control of saccadic eye movements. In the search for their functional role the present results offer the suggestion that within the frontal lobes there are mechanisms that influence how brainstem pathways mediate the "visual grasp reflex". Indeed the FEF is thought to influence activity in the SC via the direct FEF-SC projection (Guitton and Mandl 1974, 1976; Künzle and Akert 1977; Leichnetz 1980, 1981; Leichnetz et al. 1981; Stanton et al. 1982), and the FEFcaudate-substantia nigra- SC projection (Hikosaka and Wurtz 1983a-d; Zee 1984). The former may subserve activation of the $\mathrm{SC}$ and the latter may 
provide a mechanism for simultaneously eliminating tonic nigro-tectal inhibition thereby premitting SC cells to increase their discharge before visuallytriggered saccades and when the FEF is removed, the SC may be less tonically inhibited (ME Goldberg, personal communication).

\section{Functional interpretations}

Reflex cancellation. Hallett and Adams (1980) have noted that the anti-saccade task resembles the well studied "pulse-over-return" tracking task (Wheeless et al.1966; Lisberger et al.1975; Becker and Jürgens 1979) in which a target is stepped back across the primary position through an angle of say $24^{\circ}$ to an equal and opposite position $12^{\circ}$ right. The fundamental difference between the two experimental conditions is that in the anti-saccade task the second target step is formulated mentally rather than being produced visually.

In the "pulse-over-return" experiments the eye movement response can consist of either one saccade to the goal located at the final target step or a sequence of two saccades to the first and second target positions respectively. These response types are analogous, in the present study, to either a single correct anti-saccade (Fig. 5A) or to a sequence of two saccades consisting of a reflexive glance followed by a corrective anti-saccade that brings the eye to the position of the symbol (Fig. 5B)

The first target step starts a sequence of operations designed to generate a saccade and there is a critical time in this sequence beyond which other signals cannot prevent the saccade's occurrence. Whether or not the response in the "pulse-overreturn" paradigm consists of one or two saccades has been found to depend on the time by which the second target step precedes the saccadic eye movement response to the first step (Lisberger et al. 1975; Becker and Jürgens 1979). If this time interval is too short there is no time available for cancelling the first saccade and the response consists of two saccades. Conversely, if this time interval is sufficiently long, the first saccade can be cancelled and the response consists of only a single saccade to the goal position determined by the second target step. There exists a critical time interval for which $50 \%$ of the trials yield one saccade and $50 \%$, two saccades.

It is therefore possible, in the anti-saccade task, to define for any given subject a critical mean time $\left(\mathrm{T}_{\text {crit }}\right)$, following the onset of the cue, at which the action of a cancellation signal will yield reflexive glances in $50 \%$ of the trials. Suppose a subject generates a cancellation signal at time $T_{c}$. The "pulse- over-return" experiments suggest a time gate of 100 ms within which the cancellation signal must act: if $T_{c}$ $\geq \mathrm{T}_{\text {crit }}+50 \mathrm{~ms}$ the reflexive glance will never be cancelled whereas if $\mathrm{T}_{\mathrm{c}} \leq \mathrm{T}_{\text {crit }}-50 \mathrm{~ms}$ the reflexive glance will always be cancelled. Note further that $T_{\text {crit }}$ will be a function of the subject's reflexive glance latency: subjects with short reaction times will require an early cancellation signal (small $\mathrm{T}_{\text {crit }}$ ), whereas subjects with long reaction times will have more time available for cancellation (long $\mathrm{T}_{\text {crit }}$ ) (Lisberger et al. 1975; Becker and Jürgens 1979).

These arguments state that frontal patients made frequent reflexive glances because they took to long to generate the cancellation signal. The present results suggest further that $T_{c}$ is directly proportional to the quantity (Q) of information processing required by the task and inversely proportional to the rate $(\mathrm{R})$ at which this information can be processed by the nervous system. Thus suppose $T_{c} \alpha Q / R$. The non-specific effect of frontal lesions seems generally to decrease $R$. Thus in some patients like EK, R might have been so low and therefore $T_{c}$ so large $\left(T_{c}>T_{\text {crit }}\right.$ $+50 \mathrm{~ms}$ ) that the reflex was never cancelled in the standard experimental paradigm even when $\triangle \mathrm{T}=$ $600 \mathrm{~ms}$. However, cancellation became possible when $\triangle \mathrm{T}$ was increased to $800 \mathrm{~ms}$ since in this condition the latency of reflexive glances also increased from $191 \mathrm{~ms}$ to $246 \mathrm{~ms}$ (see Results: effect of changing task difficulty) thereby increasing $T_{\text {crit }}$. When the task was simplified by not requiring a symbol identification process, EK's reflexive glance latency did not increase beyond $246 \mathrm{~ms}$, yet the frequency of reflexive glances diminished still further (Fig. 12). This can be explained by a reduction in $T_{c}$ caused by a decrease in $\mathrm{Q}$.

These considerations also hold for patient JF whose data were presented at length in Figs. 8 and 11. In this subject the gradual increase in the frequency of reflexive glances as $\Delta \mathrm{T}$ decreased through the range $600 \mathrm{~ms}, 500 \mathrm{~ms}$ and $400 \mathrm{~ms}$ is closely tied to a corresponding decrease in the latency of reflexive glances $(270 \mathrm{~ms}, 171 \mathrm{~ms}$ and $145 \mathrm{~ms}$ respectively). Thus in JF, as task difficulty increased, $T_{\text {crit }}$ decreased and $T_{c}$ could not be reduced accordingly to provide adequate cancellation.

Interestingly in patient JF the tendency to generate reflexive glances was limited to contralateral cue positions. Since the latency of reflexive glances in this patient was about equal for ipsilateral and contralateral cue positions ( $140 \mathrm{~ms}$ versus $149 \mathrm{~ms}$ respectively and therefore $T_{\text {crit }}$ independent of side) the poorer performance for contralateral cue positions was presumably due to a poorer cancellation process $\left(T_{c}\right.$ longer) in the damaged hemisphere. The compara- 
tive location of lesions in patients JR, JF and MT reemphasizes that $T_{c}$ might be increased by lesions located almost anywhere in the frontal lobe; presumably via a decrease in $R$.

It is of interest to consider why patient MS, with an almost complete right prefrontal removal, did not make an abnormal number of reflexive glances in the difficult anti-saccade task (Fig. 13). In this patient the latency of reflexive glances was very high (mean $274 \mathrm{~ms}$ ) and therefore $\mathrm{T}_{\text {crit }}$ was long enough that $\mathrm{T}_{\mathrm{c}}$ was maintained constant at a value adequate for cancelling the reflexive glance.

Note that the present observations do not suggest that a cancellation signal is generated necessarily by frontal structures; only that its time of occurrence is influenced by frontal lobe malfunction. Indeed, studies of FEF neurons during visuomotor behavior in monkey have not revealed units that discharge consistently when the monkey does not look at a peripheral target (Bruce and Goldberg 1985). Furthermore, unit discharges which are usually related to movement may occur occasionally when no saccade is made, thereby suggesting that an incipient saccade has been cancelled elsewhere.

Generation of anti-saccades. The results have shown also that lesions implicating the FEF and possibly the SMA do not impair pro-saccades but drastically impair the capability to generate anti-saccades irrespective of whether or not a reflexive glance was generated. An important feature of this more specific deficit was the very short latency at which the saccades were eventually generated following the onset of the symbol. Very short latency $(70 \mathrm{~ms})$ saccades can be generated by the monkey when it has broken fixation of the central fixation point (Fischer and Boch 1983; Boch et al. 1984; Fischer et al. 1984). This suggests that the nervous system of the affected patients had been able to perform many of the computations necessary to generate the anti-saccade but that were missing an internal trigger signal. For example it is now believed that saccade genesis requires the prior calculation of the position of the target relative to the head which is then reconverted to a motor error signal in the SC and FEF (Mays and Sparks 1980; Goldberg and Bruce 1981). The very short latency of the visually triggered movements in our study is little more than the sum of retinal delays (say $35 \mathrm{~ms}$ ) and SC delays (say 20-75 ms) (Hallett and Adams 1980). This suggest in agreement with Goldberg and Bruce (1981) that the FEF and (and SMA?) are not implicated in calculating target position relative to the head. The results suggest rather that in our severely deficient patients the antisaccade generation process required only a visual signal to trigger the SC's output and that the trigger signal was normally provided by their missing brain structures. More generally, the FEF (and SMA?) are not necessary to move the eyes to a visual target even if after a brief target appearance the eyes are displaced in the dark by electrical stimulation before the orienting saccade has begun (Schiller and Sandell 1982). Rather these structures appear crucial to the more complex task whereby a visual stimulus itself is not the target but defines a new target on the basis of prior instructions.

General considerations. During our daily activities we are constantly inundated with a rich repertoire of sensory signals and the incapacity to prevent automatic "reflex-like" responses to these inputs can be interpreted as a major degradation in behaviour. The present experiments have emphasized how just a small increase in neural processing times can lead to a totally inappropriate oculomotor behaviour. An increase in the rate of signal processing caused by a frontal lobe lesion, may lead to a cancellation signal which appears $100 \mathrm{~ms}$ later than it should and this may make the difference between $0 \%$ and $100 \%$ in the frequency of reflexive glances. If the signal appears $50 \mathrm{~ms}$ rather than $100 \mathrm{~ms}$ later, an increase from 25 to $75 \%$ in frequency might be expected (Lisberger et al. 1975). Such considerations suggest that non-specific frontal lobe syndromes such as excessive reactivity to stimuli, motor hyperactivity and abnormal distractability (Fuster 1981) can be caused by a single factor: a small increase in the time taken by the frontal lobes to abort the inappropriate behavior.

Acknowledgements. We are grateful to: Drs. W. Feindel, A. Olivier, T. Rasmussen and J.G. Villemure for the opportunity to study patients under their care; Dr. B. Milner, Mr. L. Taylor and other members of the neuropsychology group at the Montreal Neurological Institute (MNI) for their help and critical comments; Ms. G. Robillard for secretarial assistance; and the MNI neurophotography group for the illustrations. R.M. Douglas was funded by a National Science and Engineering Research Council post-doctoral fellowship. D. Guitton held a Medical Research Council of Canada (MRC) scholarship. This study was supported by MRC grants MT-2624 to B. Milner and MA-7076 to D. Guitton.

\section{References}

Albano JE, Mishkin M, Westbrook LE, Wurtz RH (1982) Visuomotor deficits following ablation of monkey superior colliculus. J Neurophysiol 48: 338-351

Becker W, Jürgens R (1979) An analysis of the saccadic system by means of double step stimuli. Vision Res 19: 967-983

Bianchi L (1895) The functions of the frontal lobes. Brain 18: $497-522$

Bizzi E (1968) Discharge of frontal eye field neurons during 
saccadic and following eye movements in unanesthetized monkeys. Exp Brain Res 6: 69-80

Boch R, Fischer B, Ramsperger E (1984) Express-saccades of the monkey: Reaction times versus intensity, size, duration and eccentricity of their targets. Exp Brain Res 55: 223-231

Bruce CJ, Goldberg ME (1981) Frontal eye fields in monkey: classification of neurons discharging before saccades. Soc Neurosci Abstr 7: 131

Bruce CJ, Goldberg ME (1985) Primate frontal eye fields: I. Single neurons discharging before saccades. J Neurophysiol (in press)

Butter CM (1964) Habituation of responses to novel stimuli in monkeys with selective frontal lesions. Science 144: 313-315

Conel JL (1939-1963) The postnatal development of human cerebral cortex, Vols 1-6. Harvard University Press, Cambridge

Crowne DP, Yeo CH, Russell IS (1981) The effects of unilateral frontal eye field lesions in the monkey: visual-motor guidance and avoidance behaviour. Behav Brain Res 2: 165-187

Ferguson GA (1981) Statistical analysis in psychology and education (5. edn). McGraw Hill, New York

Fischer B, Boch R (1983) Saccadic eye movements after extremely short reaction times in the monkey. Brain Res 260: 21-26

Fischer B, Boch R, Ramsperger E (1984) Express-saccades of the monkey: effect of daily training on probability of occurrence and reaction time. Exp Brain Res 55: 232-242

Fuster JM (1981) Prefrontal cortex in motor control. In: Brooks VB (ed) Sect 1, The nervous system. Am Physiol Soc, Bethesda (Handbook of Physiology), pp 1149-1178

Goldberg ME, Bruce CJ (1981) Frontal eye fields in the monkey: eye movements remap the effective coordinates of visual stimuli. Soc Neurosci Abstr 7: 131

Goldberg ME, Bushnell MC (1981) Behavioral enhancement of visual responses in monkey cerebral cortex. II. Modulation in frontal eye fields specifically related to saccades. J Neurophysiol 46: 773-787

Guitton D, Buchtel HA, Douglas RM (1982) Disturbances of voluntary saccadic eye movement mechanisms following discrete unilateral frontal lobe removals. In: Lennerstrand $G$, Zee DS, Keller EL (eds) Functional basis of ocular motility disorders. Academic Press, Oxford, pp 497-499

Guitton D, Mandl G (1974) The effect of frontal eye field stimulation on unit activity in the superior colliculus of the cat. Brain Res 68: 330-334

Guitton D, Mandl G (1976) The convergence of inputs from the retina and the frontal eye fields upon the superior colliculus in the cat. Exp Brain Res Suppl 1: 556-562

Hallett PE (1978) Primary and secondary saccades to goals defined by instructions. Vision Res 18: 1279-1296

Hallett PE, Adams BD (1980) The predictability of saccadic latency in a novel voluntary oculomotor task. Vision Res 20 : 329-339

Hannon R, Kamback (1972) Effects of dorsolateral frontal lesions on responsiveness to various stimulus parameters in the pigtail monkey. Exp Neurol 37: 1-13

Heilmann KM, Valenstein E (1972) Frontal lobe neglect in man. Neurology 22: 660-664

Hess S, Burgi S, Bucher V (1946) Motor function of tectal and tegmental area. Mschr Psychiat Neurol 112: 1-52

Hikosaka O, Wurtz RH (1983a) Visual and oculomotor functions of monkey substantia nigra pars reticulata. I. Relation of visual and auditory responses to saccades. J Neurophysiol 49: 1230-1253

Hikosaka O, Wurtz RH (1983b) Visual and oculomotor functions of monkey substantia nigra pars reticulata. II. Visual responses related to fixation of gaze. J Neurophysiol 49: 1254-1267
Hikosaka O, Wurtz RH (1983c) Visual and oculomotor functions of monkey substantia nigra pars reticulata. III. Memory contingent visual and saccade responses. J Neurophysiol 49: 1268-1284

Hikosaka O, Wurtz RH (1983d) Visual and oculomotor functions of monkey substantia nigra pars reticulata. IV. Relation of substantia nigra to superior colliculus. J Neurophysiol 49 : $1285-1301$

Holmes $G$ (1938) The cerebral integration of ocular movements. Br Med J 2: 107-112

Jeannerod M (1972) Rôle du cortex frontal dans la motricité oculaire. Rev Otoneuro-Ophtal 44: 187-203

Jeannerod M, Kiyono S, Mouret J (1968) Effets des lésions frontales bilatérales sur le comportement oculo-moteur chez le chat. Vision Res 8: 575--582

Kennard MA, Ectors L (1938) Forced circling in monkeys following lesions of the frontal lobes. $J$ Neurophysiol 1: 45-54

Künzle H, Akert K (1977) Efferent connections of cortical area 8 (frontal eye fiels) in Macaca fascicularis. A reinvestigation using the autoradiographic technique. J Comp Neurol 173: 147-164

Kuypers HGJM, Lawrence DG (1967) Cortical projections to the red nucleus and the brain stem in the Rhesus monkey. Brain Res 4: $151-188$

Latto R, Cowey A (1971a) Visual field defects after frontal eyefield lesions in monkeys. Brain Res 30: 1-24

Latto R, Cowey A (1971b) Fixation changes after frontal eye-field lesions in monkeys. Brain Res 30: 25-36

Leichnetz GR (1980) An anterogradely-labeled prefrontal corticooculomotor pathway in the monkey demonstrated with HRP gel and TMB neurohistochemistry. Brain Res 198: 440-445

Leichnetz GR (1981) The prefontal cortico-oculomotor trajectories in the monkey. J Neurol Sci 49: 387-396

Leichnetz GR, Spencer RF, Hardy SGP, Astruc J (1981) The prefrontal corticotectal projection in the monkey: an anterograde and retrograde horseradish peroxidase study. Neuroscience 6: 1023-1041

Lisberger SG, Fuchs AF, King WM, Evinger LC (1975) Effect of mean reaction time on saccadic responses to two step stimuli with horizontal and vertical components. Vision Res 15: 1021-1025

Mays L, Sparks DL (1980) Dissociation of visual and saccaderelated responses in superior colliculus neurons. J Neurophysiol 43: 207-232

Melamed E, Larsen B (1979) Cortical activation pattern during saccadic eye movements in humans: localization by focal cerebral blood flow increases. Ann Neurol 5: 79-88

Milner B (1975) Psychological aspects of focal epilepsy and its neurosurgical management. In: Purpura DP, Penry JK, Walter RD (eds) Advances in neurology. Raven Press, New York, pp 299-321

Mishkin M (1964) Perseveration of central sets after frontal lesions in monkeys. In: Warren JM, Akert $\mathrm{K}$ (eds) The frontal granular cortex and behavior. McGraw-Hill, New York, pp 219-241

Moll L, Kuypers HGJM (1977) Premotor cortical ablations in monkeys: contralateral changes in visually guided reaching behaviour. Science 198: 317-319

Pandya DN, Vignolo LA (1971) Intra- and interhemispheric projections of the precentral premotor and arcuate areas in the rhesus monkey. Brain Res 26: 217-233

Penfield W, Jasper H (1954) Epilepsy and the functional anatomy of the human brain. Little Brown \& Co., Boston

Penfield W, Boldrey E (1937) Somatic motor and sensory representation in the cerebral cortex of man as studied by electrical stimulation. Brain 60: 389-443 
Penfield W, Rasmussen T (1950) The cerebral cortex in man. Macmillan, New York

Pribram KH (1961) A further experimental analysis of the behavioral deficit that follows injury to the primate frontal cortex. Exp Neurol 3: 432-466

Rasmussen T, Penfield W (1948) Movement of head and eyes from stimulation of human frontal cortex. Res Publ Assoc Res Nerv Ment Dis 27: 346-361

Robinson DA (1981) Control of eye movements. In: Brooks VB (ed) Sect 1, The nervous system. Am Physiol Soc, Bethesda (Handbook of Physiology)

Robinson DA, Fuchs AF (1969) Eye movements evoked by stimulation of the frontal eye fields. J Neurophysiol 32: 637-648

Schiller PH, Koerner F (1971) Discharge characteristics of single units in superior colliculus of the alert rhesus monkey. J Neurophysiol 34: 920-936

Schiller PH, Stryker M (1972) Single-unit recording and stimulation in superior colliculus of the alert rhesus monkey. J Neurophysiol 35: 915-924

Schiller PH, Sandell JH (1983) Interactions between visually and electrically elicited saccades before and after superior colliculus and frontal eye field ablations in the rhesus monkey. Exp Brain Res 49: 381-392

Schiller PH, True SD, Conway JL (1980) Deficits in eye movements following frontal eye-field and superior colliculus ablations. J Neurophysiol 44: 1175-1189
Sparks DL, Mays LE (1980) Movement fields of saccade-related burst neurons in the monkey superior colliculus. Brain Res 190: $39-50$

Sparks DL, Porter JD (1983) Spatial localization of saccade targets. II. Activity of superior colliculus neurons preceding compensatory saccades. J Neurophysiol 49: 64-74

Stanton GB, Bruce C, Goldberg ME (1982) Organization of subcortical projections from saccadic eye movement sites in the macaque's frontal eye fields. Soc Neurosci Abstr 8: 293

Welch K, Stuteville P (1958) Experimental production of unilateral neglect in monkeys. Brain 81: 341-347

Wheeless LL, Boynton RM, Cohen GH (1966) Eye-movement responses to step and pulse-step stimuli. J Opt Soc Am 56: 956-960

Wurtz RH, Albano JE (1980) Visual-motor function of the primate superior colliculus. Ann Rev Neurosci 3: 189-226

Wurtz RH, Mohler CW (1976) Enhancement of visual responses in monkey striate cortex and frontal eyefields. J Neurophysiol 39: 766-772

Zee DS (1984) Ocular motor control: the cerebral control of saccadic eye movements. In: Lessell S, van Dalen JTW (eds) Neuro-Ophthalmology, Vol 3. Elsevier, Amsterdam New York Oxford, pp 141-156

Zernicki B (1972) Orienting response hypernormality in frontal cats. Acta Neurobiol Exp 32: 393-415

Received July 12, 1984 / Accepted December 6, 1984 